\title{
Sistem Informasi Administrasi Pada Madrasah Ibtidaiyah Rare Muchtary
}

\author{
Muh. Lutfi Junaidi ${ }^{1}$, Putu Sugiartawan ${ }^{2}$ \\ ${ }^{1,2}$ Teknik Informatika, STMIK STIKOM Indonesia, Bali, Indonesia \\ e-mail: ${ }^{1}$ lutfi.junaidi@stiki-indonesia.ac.id, ${ }^{\text {²}}$ putu.sugiartawan@stiki-indonesia.ac.id
}

\begin{abstract}
Abstrak
Teknologi komputer saat ini banyak dimanfaatkan dalam dunia bisnis bahkan dunia Pendidikan saat ini banyak yang mengaplikasikan penggunaan teknologi komputer ini. Tanpa menggunakan komputer, suatu pekerjaan akan banyak membuang waktu, tenaga, dan pikiran. Dalam upaya meningkatkan mutu sumber daya manusia (SDM) dan kelancaran proses administrasi khususnya pada sistem pembayaran administrasi dibutuhkan kecepatan dan ketepatan dalam waktu pengerjaan sehingga dalam proses pembayaran wali murid tidak perlu menunggu terlalu lama. MI Rare Muchtary adalah sebuah sekolah Madrasah Ibtidaiyah yang berada dibawah naungan Yayasan SPMAA. Pembayaran administrasinya masih menggunakan cara yang manual dengan memberikan kwitansi sebagai bukti pembayaran kemudian dicatat dalam laporan penerimaan pembayaran sehingga rentan terjadi kesalahan oleh petugas. Baik dalam pencatatan data pembayaran maupun dalam pengumpulan data pembayaran administrasi untuk dijadikan laporan keuangan, mengingat terkadang petugas sering lupa untuk membuat kwitansi/bukti pembayaran. Berdasarkan latar belakang tersebut maka dirancang sebuah system informasi pembayaran administrasi yang kemudian akan dijadikan studi. kasus dari laporan kerja praktek dengan judul "Perancangan Sistem Informasi Pembayaran Administrasi Berbasis Website", agar dapat mempermudah petugas dalam mencatat data pembayaran administrasi.
\end{abstract}

Kata kunci-Teknologi Informasi, Sistem Infromasi, administrasi, Pambayaran

\begin{abstract}
Computer technology is currently widely used in the business world and even in the world of education today many are applying the use of this computer technology. Without using a computer, a job will waste a lot of time, energy, and thought. In an effort to improve the quality of human resources (HR) and the smooth running of the administrative process, especially in the administrative payment system, speed and accuracy are needed in processing so that the student guardian does not have to wait too long in the payment process. MI Rare Muchtary is a Madrasah Ibtidaiyah school under the auspices of the SPMAA Foundation. Administrative payments are still using the manual method by providing a receipt as proof of payment and then recording in the payment receipt report so that it is prone to errors by officers. Both in recording payment data and in collecting administrative payment data to be used as financial reports, considering that sometimes officers often forget to make receipts/proof of payment. Based on this background, an administrative payment information system is designed which will then be used as a study. a case from a practical work report with the title "Website-Based Administration Payment Information System Design", in order to make it easier for officers to record administrative payment data.
\end{abstract}

Keywords—Information Technology, Information Systems, Administration, Payment

Received Februari $1^{\text {st }}, 2020$; Revised Februari 25 ${ }^{\text {th }}, 2020$; Accepted Maret $10^{\text {th }}, 2020$ 


\section{PENDAHULUAN}

Seiring dengan perkembangan zaman dan perkembangan teknologi yang semakin pesat,

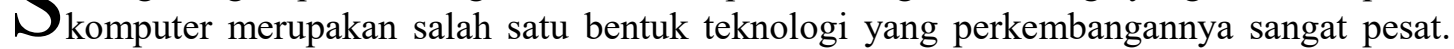
Menurut [1] Teknologi adalah penerapan dari ilmu atau pengetahuan lain yang terorganisir ke dalam tugas-tugas praktis. Komputer tidak hanya dimanfaatkan oleh pihak yang mempunyai kepentingan saja. Teknologi komputer saat ini banyak dimanfaatkan dalam dunia bisnis bahkan dunia Pendidikan saat ini banyak yang mengaplikasikan penggunaan teknologi komputer ini. Dari itulah muncul yang namanya teknologi informasi yang banyak memiliki manfaat bagi kegiatan manusia saat ini. Teknologi informasi adalah suatu teknologi yang digunakan untuk mengolah data, termasuk memproses, mendapatkan, menyusun, menyimpan, memanipulasi data dalam berbagai cara untuk menghasilkan informasi yang berkualitas, yaitu informasi yang relevan, akurat dan tepat waktu, yang digunakan untuk keperluan pribadi, bisnis, dan pemerintahan dan merupakan informasi yang strategis untuk pengambilan keputusan [2]. Tanpa menggunakan komputer, suatu pekerjaan akan banyak membuang waktu, tenaga, dan pikiran. Dalam upaya meningkatkan mutu sumber daya manusia (SDM) dan kelancaran proses administrasi khususnya pada sistem pembayaran administrasi dibutuhkan kecepatan dan ketepatan dalam waktu pengerjaan sehingga dalam proses pembayaran wali murid tidak perlu menunggu terlalu lama. Pengertian Sumber Daya Manusia adalah kemampuan terpadu dari daya pikir dan daya fisik yang dimiliki individu. Pelaku dan sifatnya dilakukan oleh keturunan dan lingkungannya, sedangkan prestasi kerjanya dimotivasi oleh keinginan untuk memenuhi kepuasannya [3]. MI Rare Muchtary adalah sebuah sekolah Madrasah Ibtidaiyah yang berada dibawah naungan Yayasan SPMAA Denpasar yang bergerak dibidang Pendidikan dan berlokasi di Jl. Gunung Lebak IV Gang Harmoni, Tegal Harum, Kec. Denpasar Barat., Kota Denpasar, Bali. Pada saat ini banyak sekali orang tua yang sibuk dengan pekerjaannya sehingga para orang tua memilih untuk memasukkan anaknnya ke pondok agar bisa di didik dan selalu diawasi setiap saat. Karena di madrasah ini, anak-anak diberi pendidikan yang sesuai dengan kurikulum yang ada. Disini juga anak-anak didampingi untuk belajar mengaji, bermain, dan masih banyak kegiatan sosial lainnya yang diajarkan untuk ditanamkan pada si anak, terlebih lagi para pendidik di MI Rare Muchtary ini sudah berpengalaman. Namun di dalam perkembangan teknologi informasi yang juga sudah merambat ke dunia Pendidikan dan bisnis, MI Rare Muchtary proses.

\section{METODE PENELITIAN}

\subsection{Analisis Sistem}

Sistem adalah sekumpulan elemen yang saling terkait atau terpadu yang dimaksudkan untuk mencapai tujuan [4]. Analisis sistem merupakan tahapan paling awal dari pengembangan sistem yang menjadi fondasi menentukan keberhasilan sistem informasi yang dihasilkan nantinya. Analis sistem adalah sebuah istilah yang secara kolektif mendeskripsikan fase-fase awal pengembangan awal [5]. Tahap analisis akan dilakukan untuk menguraikan suatu system informasi yang utuh ke dalam bagian-bagian komponennya. Tahap ini juga bertujuan untuk memecahkan masalah yang sudah ada dengan mempelajari sistem dan proses kerja untuk mengidentifikasi kelemahan dan peluang untuk perbaikan. Adapun Analisa kebutuhan sistem dalam merancang system informasi pembayaran administrasi pada Madrasah Ibtidaiyah Rare Muchtary.

\section{2 Administrasi}

Administrasi adalah usaha dan kegiatan yang meliputi penetapan cara-cara penyelenggaraan pembinaan organisasi. Administrasi dapat diartikan sebagai segala kegiatan yang perlu dijalankan untuk dapat mencapai suatu tujuan tertentu yang telah direncanakan 
sebelumnya Kegiatan-kegiatan itu adalah antara lain menentukan kebijakan, membuat rencana, membagi-bagi tugas, menyusun aturan pelaksanaan, mengawasi dan membimbing pelaksanaan dan penilaian yang menuju kepada keberhasilan dari suatu usaha.

Statement Of Purpose atau Standar Operasional Prosedur adalah suatu standar dan prosedur yang digunakan sebagai acuan dalam bekerja dan digunakan pula untuk mengukur kinerja atau sebagai tolok ukur dalam menilai kinerja pegawai di suatu perusahaan swasta maupun di suatu instansi pemerintahan, agar pekerjaan dapat berjalan sesuai dengan standar dan prosedur yang ada dan yang digunakan oleh suatu perusahaan swasta maupun suatu instansi pemerintahan, maka kinerja maupun pekerjaan harus sesuai dengan SOP yang ada dan yang digunakan tersebut [6].

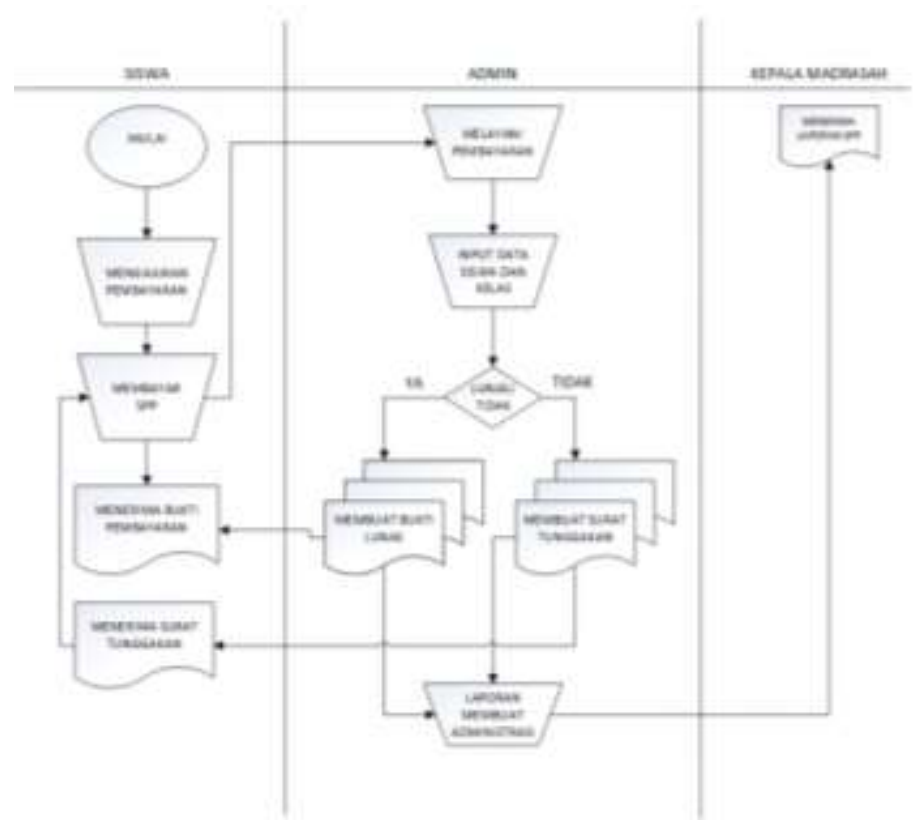

Gambar 1 Document Flow Diagram Pencatatan Pembayaran Administrasi Secara Manual

\subsection{Analisis Proses yang Sedang Berjalan}

Analisis sistem yang sedang ebrjalan secara keseluruhan sangat perlu bagi penulis untuk dapat mengetahui kelemahan dari pencatatan secara manual tersebut. Berdasarkan observasi yang dilakukan penulis pada Madrasah Ibtidaiyah Rare Muchtary, mekanisme kerja sistem yang berjalan yaitu yang pertama admin mencatat data pembayaran administrasi, kemudian admin merekap laporan di akhir bulan. Selanjutnya admin memberikan hasil rekapan laporan pembayaran kepada kepala sekolah di setiap bulan yang sudah dicatat oleh admin.yang ditunjukan oleh Gambar 1.

\section{4 Analisis Sistem yang Telah Diusulkan}

Menurut Setelah melakukan analisis terhadap sistem yang sedangberjalan, penulis menyimpulkan bahwa sistem tersebut memiliki masukan proses dan keluaran. Dari hasil analisi tersebut diperlukan adanya sistem informasi yang mampu mengatasi kelemahan dan mampu mengurangi kesalahan yang terjadi dari sistem yang berjalan. Dari sistem yang berjalan mengakibatkan pencarian data yang membutuhkan waktu yang lama. Daripermasalahan yang terjadi dan berdasarkan hasil analisis sistem yang berjalan, maka penulis mengajukan rancangan sistem yang dapat membantu meminimalkan dan mengatasi permasalahan yang terjadi dari proses yang sedang berjalan. 


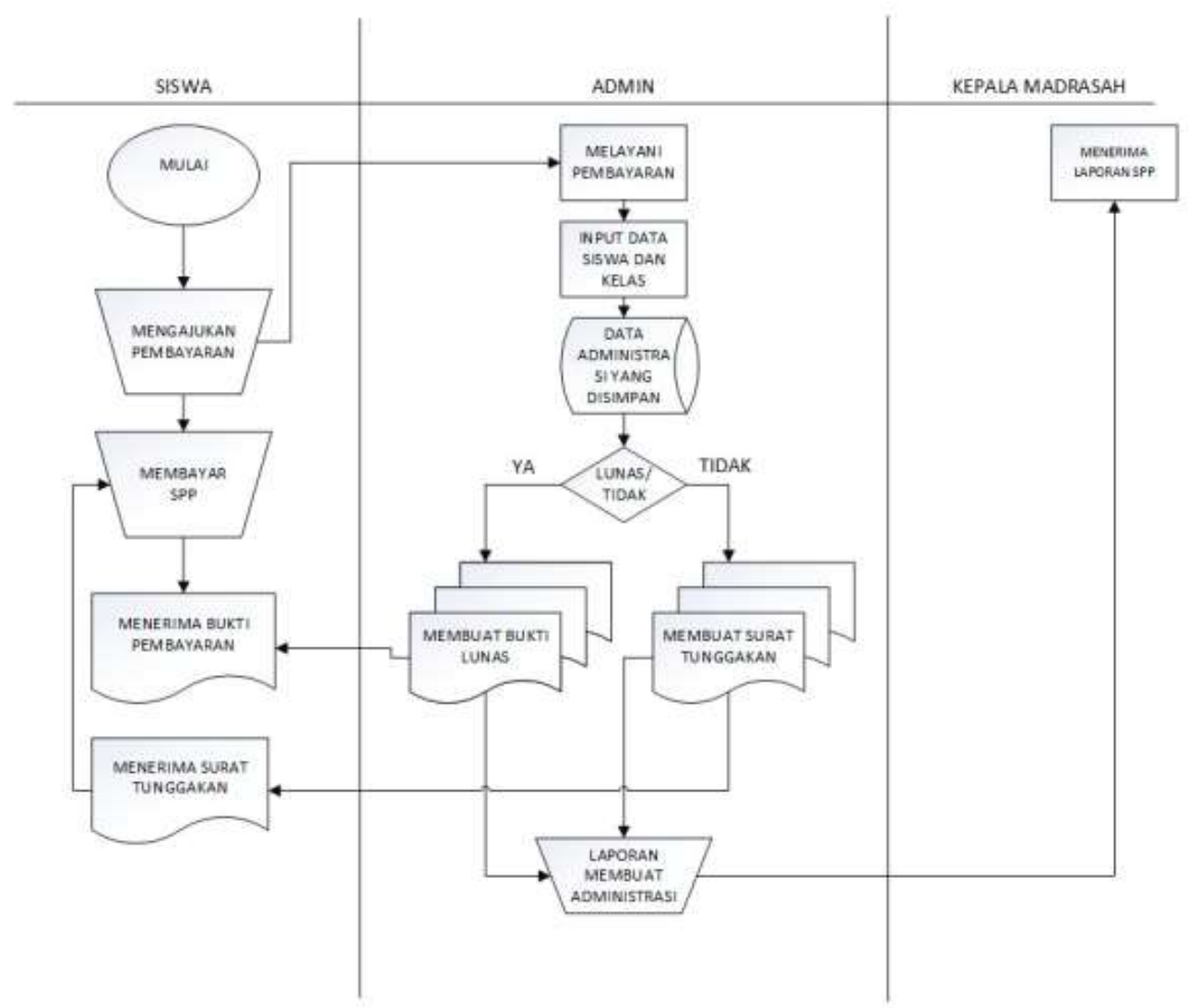

Gambar 2 Document Flow Diagram Pencatatan Pembayaran Administrasi dengan Sistem

\subsection{Data Flow Diagram (DFD)}

Data Flow Diagram (DFD) adalah alat yang dapat digunakan untuk menggambarkan sistem yang dirancang. Penggambaran DFD diawali dengan diagram konteks (CD), Penggambaran DFDlebih terfokus pada aliran proses data dalam sistem yang akan membuat pengguna lebih memahami bagaimana data mengalir dalam sistem dan bagaimana data diproses dalam sistem [7]. Diagram konteks atau Context Diagram (CD) adalah gambaran umum tentang suatu sistem yang terdapat didalam suatu organisasi yang memperlihatkan batasan (boundary) sistem, adanya interaksi antara eksternal entity dengan suatu sistem dan informasi secara umum mengalir diantara entity dan sistem. Context Diagram merupakan alat bantu yang digunakan dalam menganalisa sistem yang akan dikembangkan [8]. Diagram Konteks Gambar 2 menjelaskan alur kerja dari Sistem Informasi Pembayaran Administrasi seperti entitas karyawan TU yang bisa login. ke sistem kemudian dapat menginputkan data siswa, data kelas, dan data pembayaran administrasi. Kemudian admin dapat mengelola data laporan transaksi pembayaran administrasi lalu akan dicetak oleh admin dan hasil cetak tersebut akan diberikan kepada kepala sekolah.

Gambar 3 adalah DFD Level Nol dari Sistem Informasi Pembayaran Administrasi pada Madrasah Ibtidaiyah Rare Muchtary yang menjelaskan seluruh tugas yang bisa dilakukan oleh masingmasing entitas, seperti entitas karyawan TU bisa login ke dalam sistem dan dapat melakukan pengelolaan data siswa, data kelas, data transaksi pembayaran dan data laporan. 


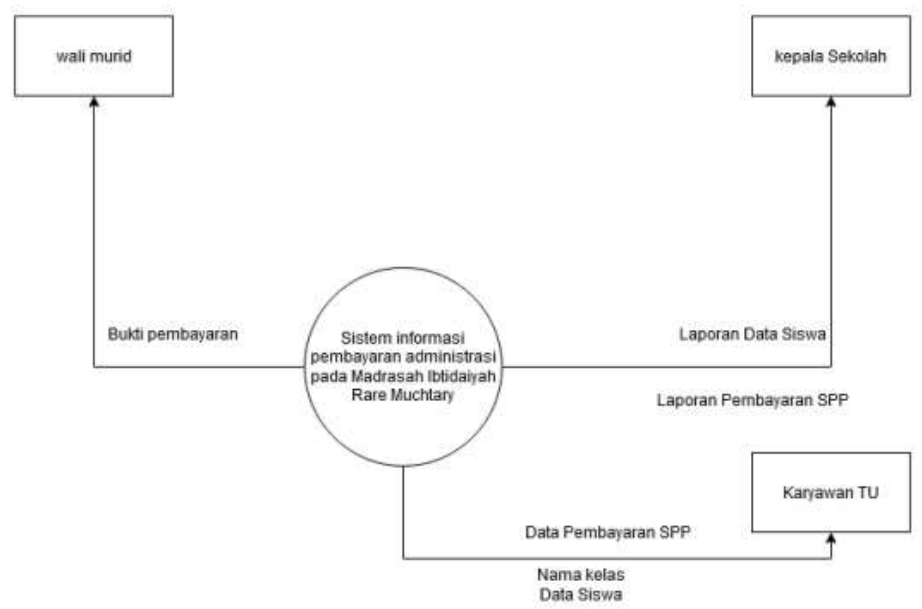

Gambar 3 DFD Level Nol

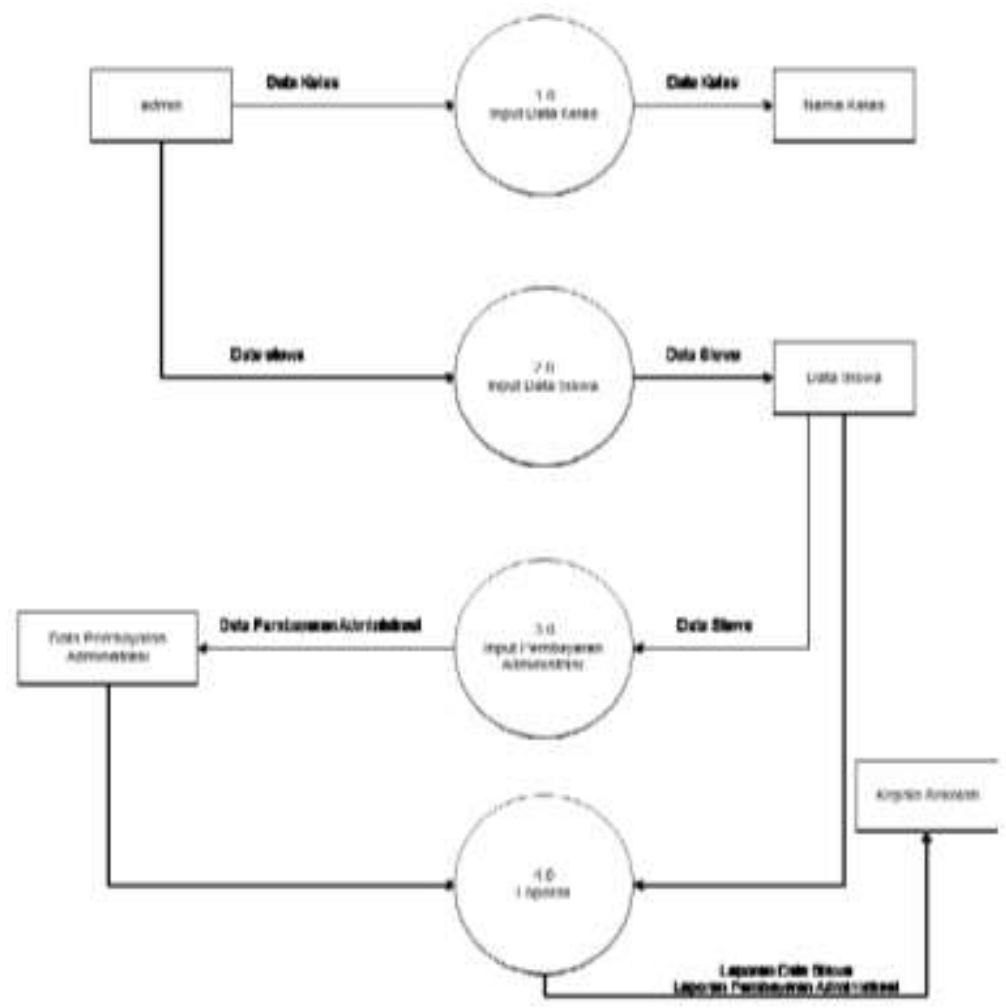

Gambar 4 Tugas Entitas Kelas

Gambar 4 menjelaskan tentang tugas entitas kelas. Yaitu entitas kelas menggambarkan proses yang terjadi dalam pengelolaan data kelas. Terdapat tiga proses yaitu proses tambah data kelas, edit data kelas, dan hapus data kelas. Entitas admin dapat melakukan proses menambah, mengubah dan menghapus data kelas yang dimana data-data tersebut akan disimpan ke dalam data kelas, 


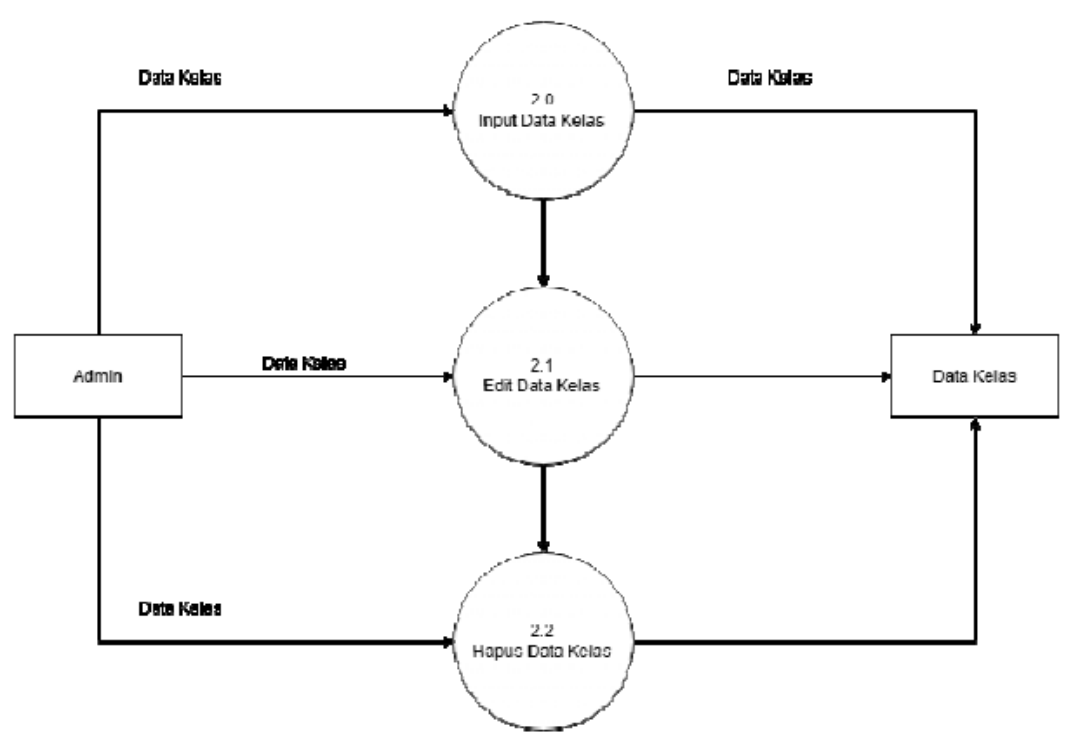

Gambar 5

\subsection{Conceptual Data}

Conceptual Data Model (CDM) merupakan model yang merepresentasikan tabel yang merupakan entitas yang berisi atribut [9]. Model perancangan sistem informasi pembayaran administrasi pada Madrasah Ibtidaiyah Rare Muchtary Berbasis Website terdiri dari 5 tabel basis data yaitu tabel petugas yang memiliki atribut id_level sebagai primary identifier, tabel siswa yang memiliki atribut NIS sebagai primary identifier, tabel kelas memiliki atribut id kelas sebagai primary identifier, tabel Data SPP yang memiliki atribut tahun_ajaran sebagai primary identifier, tabel transaksi yang memiliki atribut id_transaksi sebagai primary identifier. Tabel basis data tersebut masing-masing memiliki hubungan atau relasi dengan tabel lain. Conceptual Data Model dari sistem ini dapat dilihat pada Gambar 5.

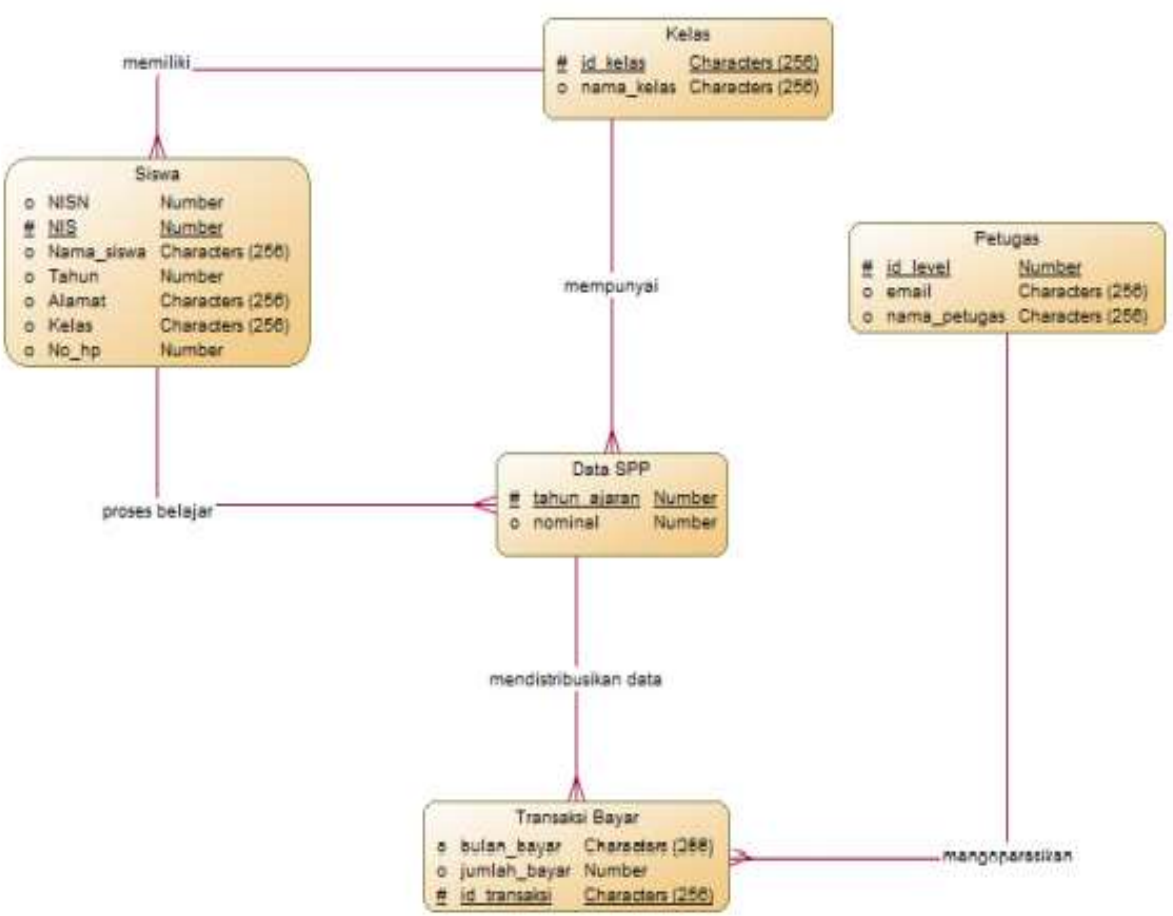

Gambar 6 Conseptual Data Model

JSIKTI Vol. 2, No. 3, Maret 2020: 48-58 


\subsection{Physical Data Model}

Physical Data Model hampir sama dengan CDM namun dalam PDM diberikan keterangan tipe data masing-masing atribut serta dijelaskan pula primary key ataupun foreign key [10]. Merupakan hasil dari generate dari bentuk Conseptual Data Model sebelumnya [11]. Pada Gambar 7 merupakan Physical Data Model dari sistem informasi pembayaran administrasi pada Madrasah Ibtidaiyah Rare Muchtary berbasis website.

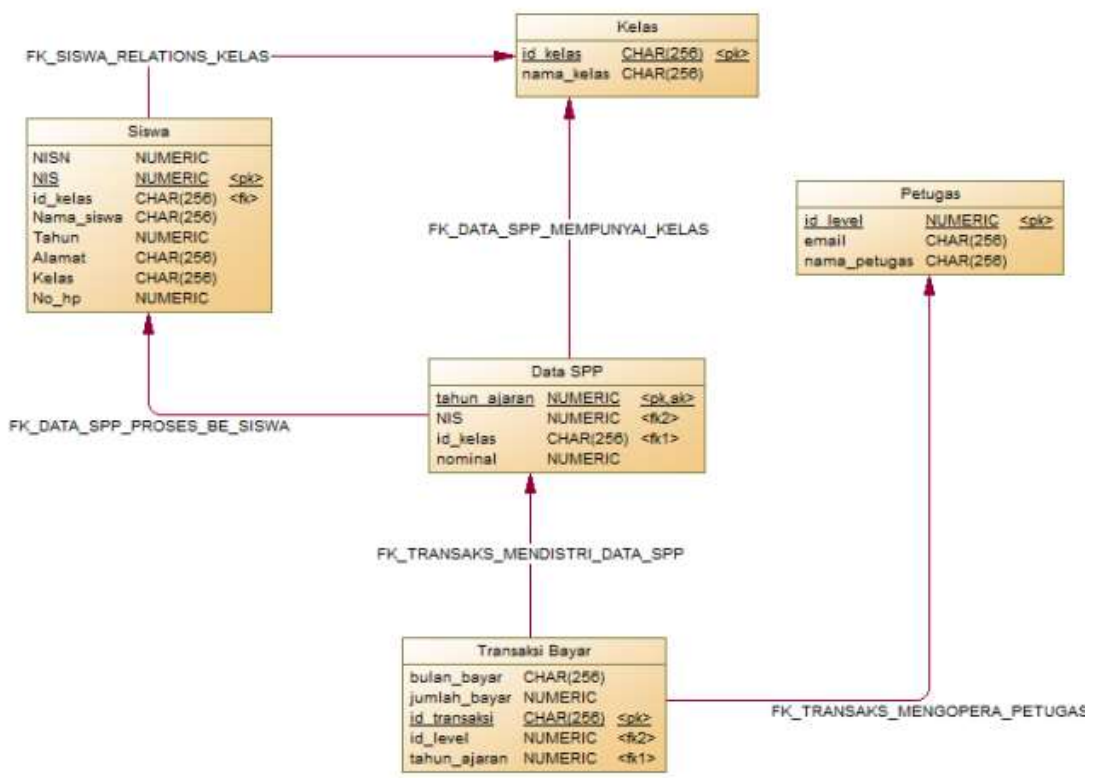

Gambar 7 Physical Data Model

\section{HASIL DAN PEMBAHASAN}

Implementasi user interface merupakan hal yang sangat penting dalam perancangan sebuah sistem. Implementasi user interface ini dapat mempermudah pengguna dalam menggunakan sistem. Berikut ini adalah implementasi user interface system informasi pembayaran administrasi pada Madrasah Ibtidaiyah rare Muchtary berbasis web.

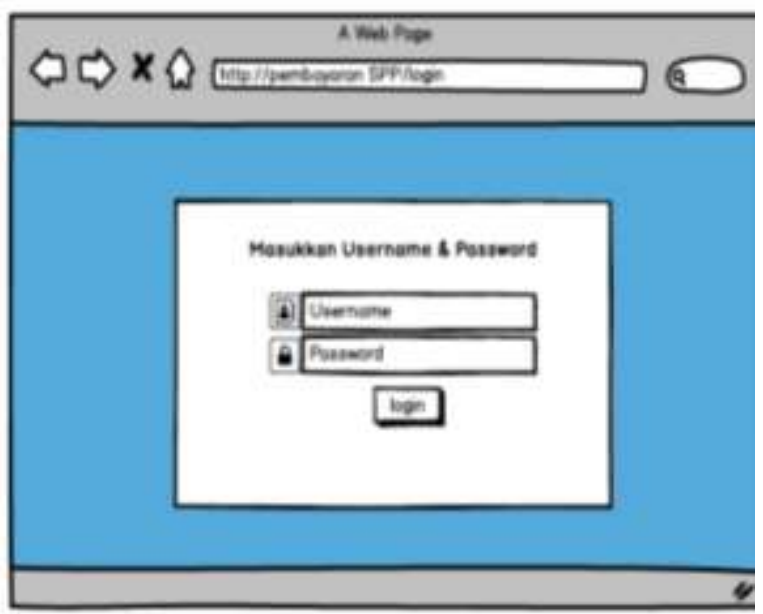

Gambar 8 Tampilan Form Login 


\subsection{Tampilan Form Login}

Sebelum menggunakan sistem, admin akan melakukan login terlebih dahulu dengan memasukkan username dan password dan menekan tombol Login. User Interface login dapat dilihat pada Gambar 8 .

\subsection{User Interface Home Admin}

Halaman home admin merupakan halaman yang akan tampil ketika admin menekan tombol home yang terdapat setelah admin berhasil login ke sistem. User interface home admin dapat dilihat pada Gambar 9.

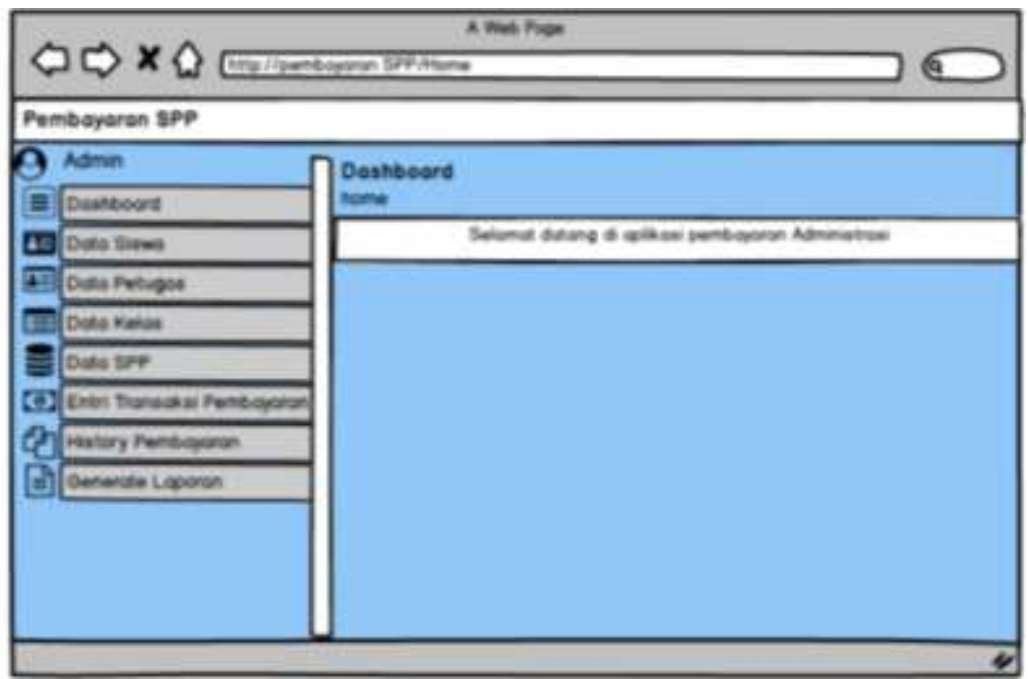

Gambar 9 User interface home admin

\subsection{Halaman data petugas}

Merupakan halaman yang akan tampil ketika admin menekan tombol data petugas. User interface data petugas dapat dilihat pada Gambar 10.

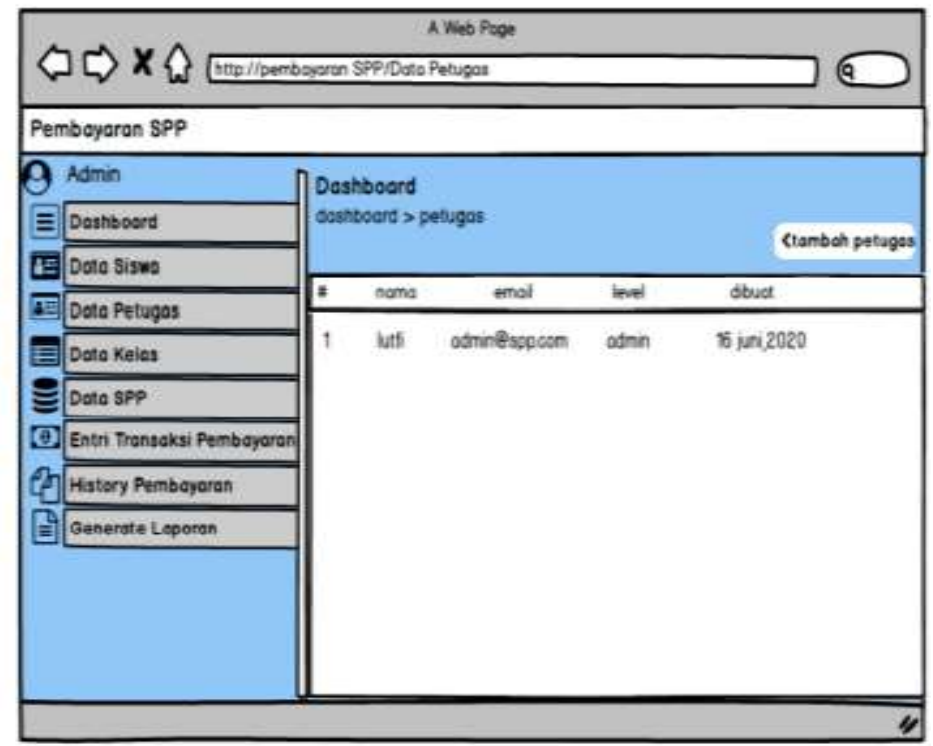

Gambar 10 Halaman data petugas

JSIKTI Vol. 2, No. 3, Maret 2020: 48-58 


\subsection{User Interfcae Tambah Data Petugas}

Halaman tambah data petugas merupakan halaman yang akan tampil ketika admin menekan tombol tambah petugas. User interface tambah data petugas dapat dilihat pada Gambar 11.

\begin{tabular}{|l||l||l|l|l|}
\hline Dashboard \\
\hline Pembayaran SPP \\
\hline Admin
\end{tabular}

Gambar 11 User Interfcae Tambah Data Petugas

\subsection{User Interface Data Pembayaran}

Halaman data pembayaran merupakan halaman yang akan tampil ketika admin menekan tombol entri transaksi pembayaran. User interface data petugas dapat dilihat pada Gambar 12.

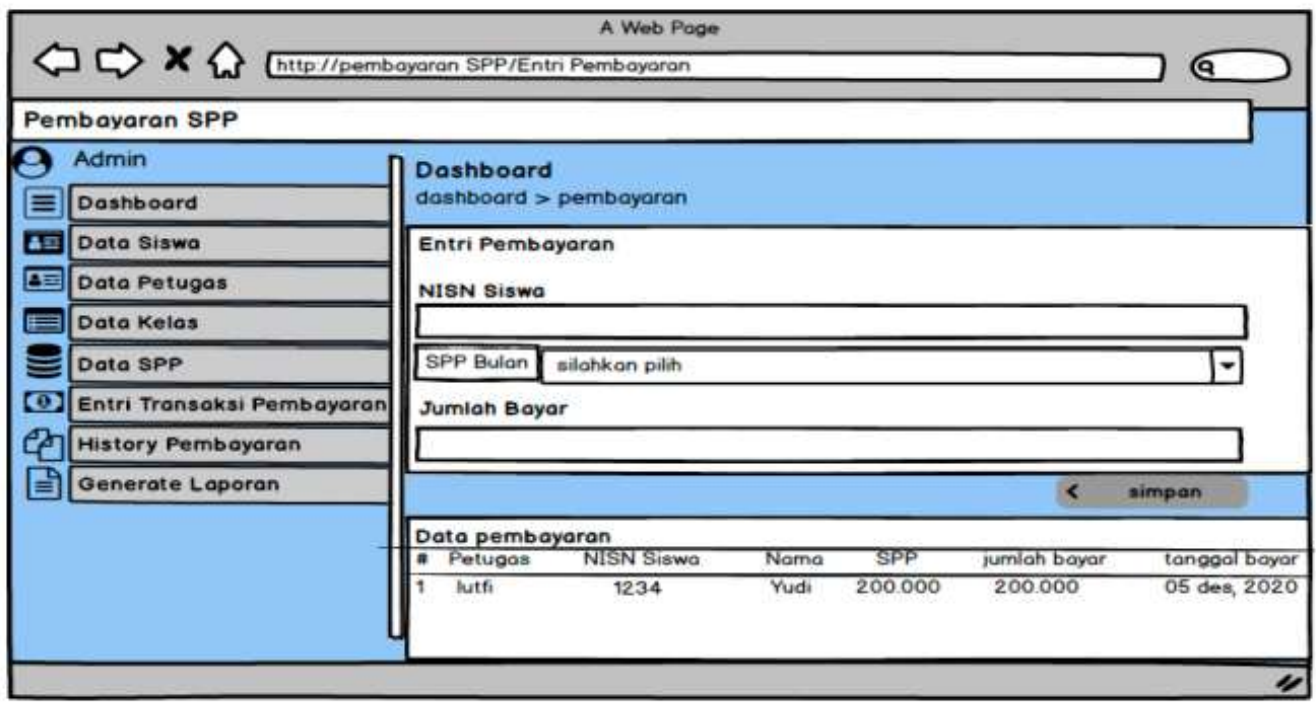

Gambar 12 User Interface Data Pembayaran 
Halaman buat laporan merupakan halaman yang akan tampil ketika admin menekan tombol generate laporan. User interface data petugas dapat dilihat pada Gambar 13,

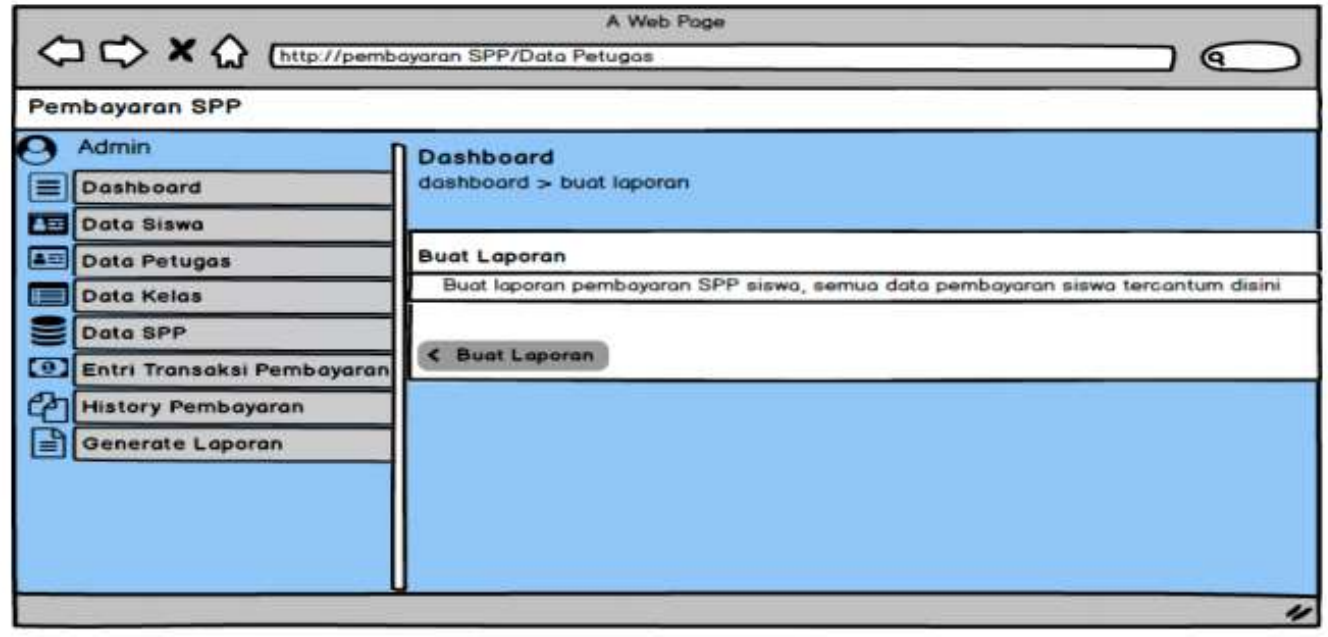

Gambar 13 User interface data petugas

\section{KESIMPULAN}

Ke Dari pembahasan laporan Sistem Informasi Pembayaran Administtrasi pada Madrasah Ibtidaiyah Rare Muchtary memiliki kesimpulan sebagai berikut, Penelitian ini diawali dengan pengumpulan data pada Madrasah Ibtidaiyah Rare Muchtary dan dengan beberapa metode yaitu metode wawancara, observasi, dan dokumentasi. Dari datadata yang telah diperoleh, peneliti menemukan kekurangan dalam sistem instansi tersebut. Sehingga peneliti mengusulkan solusi untuk mengatasi kekurangan sistem yang sedang berjalan, Solusi yang diusulkan oleh peneliti yaitu Sistem Informasi Pembayaran Administtrasi pada Madrasah Ibtidaiyah Rare Muchtary Berbasis Website. Sistem tersebut dapat mengelola data admin, data siswa, data kelas, data transaksi pembayaran, data spp, serta laporan transaksi pembayaran spp siswa, Dengan adanya perancangan sistem ini, dapat membantu memudahkan admin untuk merekapitulasi laporan transaksi pembayarn administrasi.

\section{SARAN}

Saran yang diberikan yaitu berdasarkan penelitian yang telah dilakukan, diharapkan dengan adanya laporan Sistem Informasi Pembayaran Administrasi Pada Madrasah Ibtidaiyah Rare Muchtary ini dapat menjadi referensi dalam pembuatan sistem yang berguna bagi pihak Madrasah Ibtidaiyah Rare Muchtary.

\section{DAFTAR PUSTAKA}

[1] E. Anih, "Modernisasi Pembelajaran di Perguruan Tinggi Berbasis Teknologi Informasi dan Komunikasi," J. Pendidik. Unsika, vol. 4, no. 2, pp. 185-196, 2016, [Online]. Available: http://journal.unsika.ac.id/index.php/judika.

[2] R. S. Naibaho, "Peranan Dan Perencanaan Teknologi Informasi Dalam Perusahaan," J. War., no. April, p. 4, 2017, [Online]. Available: https://media.neliti.com/media/publications/290731-peranan-dan-perencanaan-teknologiinform-ad00d595.pdf. 
[3] Kharie Andini Ramanti, S. G. M, and D. O. . Lucky, "Pengaruh Analisis Jabatan, Disiplin Kerja Dan Beban Kerja Terhadap Kinerja Karyawan Pt. Bank Rakyat Indonesia (Persero) Tbk Kantor Cabang Ternate," J. EMBA J. Ris. Ekon. Manajemen, Bisnis dan Akunt., vol. 7, no. 1, pp. 141-150, 2019, doi: 10.35794/emba.v7i1.22292.

[4] A. Asfinoza, S. Puspasari, and H. Sunardi, "Sistem Informasi Penjualan Pupuk Berbasis Web pada PT. Sri Aneka Karyatama," J. Media Infotama, vol. 14, no. 1, 2018, doi: 10.37676/jmi.v14i1.472.

[5] R. Muhidin, N. F. Kharie, and M. Kubais, "Analisis Dan Perancangan Sistem Informasi Pada Sma Negeri 18 Halmahera Selatan Sebagai Media Promosi Berbasis Web Analysis and Information System Design in Sma Negeri 18 South Halmahera As Media Promotion of Web-Based," IJIS-Indonesia J. Inf. Syst., vol. 4, no. April, pp. 69-76, 2019, [Online]. Available: https://media.neliti.com/media/publications/260171-sisteminformasi-pengolahan-data-pembeli-e5ea5a2b.pdf.

[6] T. D. Junita, "PERANAN SOP PADA ORGANISASI PEMERINTAHAN KOTA SURABAYA DALAM PENINGKATAN KEPUASAN PELAYANAN KEPADA MASYARAKAT(Studi Di Bagian Umum dan Protokol Pemerintahan Kota Surabaya)," JPAP J. Penelit. Adm. Publik, vol. 3, no. 2, pp. 858-863, 2017, doi: 10.30996/jpap.v3i2.1266.

[7] F. Soufitri, "Perancangan Data Flow Diagram Untuk Sistem Informasi Sekolah (Studi Kasus Pada Smp Plus Terpadu)," Ready Star, vol. 2, no. 1, pp. 240-246, 2019.

[8] D. Sukrianto, "Penerapan Teknologi Barcode pada Pengolahan Data Pembayaran Sumbangan Pembinaan Pendidikan (SPP)," Intra-Tech, vol. 1, no. 2, pp. 18-27, 2017.

[9] D. O. Sumadya, H. H. Ginardi, and R. J. Akbar, "Perancangan dan Implementasi Basis Data Aplikasi Web Fotokita," J. Tek. ITS, vol. 5, no. 2, pp. 2-5, 2016, doi: 10.12962/j23373539.v5i2.18771.

[10] O. Khori, "Aplikasi Android untuk Fasilitas Antar Jemput Siswa SD," J. Manaj. Inform., vol. 8, pp. 35-43, 2018.

[11] D. C. P. Diaz, Sulistiowati, and J. Lemantara, "Rancang Bangun Aplikasi Penjualan Online Issn 2338-137X," Jsika, vol. 5, no. 12, pp. 1-7, 2016, [Online]. Available: https://jurnal.stikom.edu/index.php/jsika/article/view/1480/900. 